\title{
Does Personality Moderate the Effects of Mindfulness Training for Medical and Psychology Students?
}

\author{
Michael de Vibe • Ida Solhaug • Reidar Tyssen • \\ Oddgeir Friborg • Jan H. Rosenvinge • Tore Sørlie • \\ Even Halland • Arild Bjørndal
}

Published online: 27 October 2013

(C) The Author(s) 2013. This article is published with open access at Springerlink.com

\begin{abstract}
The majority of mindfulness research to date has reported only on the group-level effects of interventions. Therefore, there is a need to better understand who is most likely to benefit from mindfulness interventions. This study reports on moderation analyses from a two-centre randomised controlled trial of mindfulness-based stress reduction (MBSR) among 288 medical and psychology students. The study investigated whether baseline personality factors (neuroticism, conscientiousness and extroversion) and baseline mindfulness moderated effects on mental distress, study stress and subjective well-being measured after the intervention. An increased effect of the intervention on mental distress and
\end{abstract}

M. de Vibe $(\square)$

Norwegian Knowledge Centre for the Health Services,

P.O. Box 90153, 0130 Oslo, Norway

e-mail:mfd@nokc.no

I. Solhaug $•$ O. Friborg $•$ J. H. Rosenvinge

Department of Psychology, Faculty of Health Sciences, University of

Tromsø, 9037 Tromsø, Norway

\section{R. Tyssen}

Department of Behavioural Sciences in Medicine, Institute of Basic Medical Sciences, Faculty of Medicine, University of Oslo,

P.O. Box 1111, 0317 Oslo, Norway

T. Sørlie

Department of Clinical Medicine, Faculty of Health Sciences,

University of Tromsø, 9037 Tromsø, Norway

E. Halland

Lovisenberg Hospital, 0440 Oslo, Norway

A. Bjørndal

Center for Child and Adolescent Mental Health, Eastern and

Southern Norway, P.O. Box 4623, 0405 Oslo, Norway subjective well-being was found in students with higher scores on neuroticism. Students with higher scores on conscientiousness showed an increased effect of mindfulness training on study stress. The training protected students against an increase in mental distress and study stress and a decrease in subjective well-being that was seen in the control group. Baseline mindfulness and extroversion did not moderate the effects of the intervention on the outcomes. The majority of the 288 medical and psychology students in the study sample were female. Female participants scored significantly higher on neuroticism and conscientiousness, and they may therefore be an important target group for mindfulness interventions among students.

Keywords Mindfulness · MBSR · Personality · Moderation · RCT $\cdot$ Students

\section{Introduction}

Research evidence has increasingly demonstrated the positive effects of mindfulness-based interventions on a range of outcomes in clinical and non-clinical populations on a group level (de Vibe et al. 2012). However, more insight is needed about who would most likely benefit from such interventions. A classic question within intervention research asks: 'What works for whom?' Mindfulness researchers, too, require a better understanding of the moderators of outcomes. Insights of this kind could also help to guide adaptations of mindfulness programmes to meet the needs of different populations (Kazdin 2008).

There are many possible factors that could moderate the effects of mindfulness training. Personality traits are among 
the likely candidates to investigate as mindfulness has been found to correlate with Eysenck's (1990) 'Big Five' personality traits of neuroticism, extroversion, openness to experience, agreeableness and conscientiousness (Giluk 2009). However, research results have been sparse, and there is a need for more studies to clarify how mindfulness relates to personality traits (Giluk 2009). This article will look at the 'Big Three' personality dimensions of neuroticism, conscientiousness and extroversion (Eysenck 1994) and whether these characteristics moderate the effects of mindfulness training.

Neuroticism has previously been found to be an important predictor of anxiety and depressive symptoms and higher levels of neuroticism (characterised by anxiety, selfconsciousness, moodiness and insecurity), predicted a better outcome following a brief mindfulness intervention in a noncontrolled study of 133 adults (Lane et al. 2007). Higher baseline levels of neuroticism were associated with greater effects on stress, mood disturbance and state anxiety at 4, 8 and 12 weeks of follow-up, respectively. Individuals with pronounced neuroticism may, however, display low levels of adherence and may find it difficult to practice mindfulness (Delmonte 1988). The difficulty of differentiating between covariate effects and regression to the mean in uncontrolled studies may therefore have affected the validity of the observations made.

Conscientiousness and extroversion may also moderate the effect of mindfulness interventions, although, to our knowledge, no studies of such effects have been reported in the literature. Conscientiousness (characterised by being responsible, rule abiding and controlling) has been found to predict student stress in medical students (Tyssen et al. 2007). However, in a meta-analysis of seven cross-sectional studies, a positive correlation between conscientiousness and mindfulness was reported (Giluk 2009). In addition, a pilot study in a non-clinical student population has shown that mindfulness training may help to reduce obsessivecompulsive symptoms (Hanstede et al. 2008). However, the relevance of this latter finding in relation to conscientiousness is uncertain. Extroversion (characterised by talkativeness, sociability and assertiveness) has been linked to subjective well-being and positive emotionality (Diener 2000) and to mindfulness (Baer et al. 2006; Brown et al. 2007), yet a meta-analysis of 11 studies has shown only a moderate positive correlation between extroversion and mindfulness (Giluk 2009).

Mindfulness has also been considered a personal characteristic, and it has been shown to be inversely related to neuroticism (Baer et al. 2006), but whether baseline levels of mindfulness moderate the effects of mindfulness training remains unclear. A small study of a mindfulness-based stress reduction (MBSR) intervention, using a sample of 30 undergraduate students, found that participants with higher levels of baseline mindfulness showed a larger increase in mindfulness, subjective well-being, empathy and hope and larger declines in perceived stress up to 1 year after the intervention, compared to the wait list control group (Shapiro et al. 2011). In an uncontrolled study where a small community sample received brief mindfulness training, no moderating effect of mindfulness on mental distress was found (Sass et al. 2013).

Previous studies, which may therefore be argued, have indicated that baseline levels of neuroticism and mindfulness may possibly moderate the effect of MBSR training on mental health outcomes, while there is only correlational evidence on the relationship between mindfulness and the personality traits of extroversion and conscientiousness. Overall, however, the research in this field remains sparse. In addition several studies were conducted without control groups and had low statistical power. The purpose of this study was to avoid these previous methodological shortcomings when examining potential moderators of the effects of mindfulness training on mental distress, student stress and well-being in medical and psychology students. Previously, we have reported that mindfulness training had a moderately large effect on mental distress and subjective well-being and a small effect on study stress among female medical and psychology students (de Vibe et al. 2013). This article presents new data from the same trial in order to investigate which students benefited the most from the mindfulness intervention.

Our hypotheses were that higher levels of neuroticism and mindfulness would predict a larger effect of the intervention on mental distress, student stress and subjective well-being. The moderation analyses for conscientiousness and extroversion are exploratory and hypothesis-generating in nature.

\section{Method}

A moderator of an intervention is a pretreatment or baseline variable that identifies subgroups within the population with a different effect of the intervention (Kraemer et al. 2006).

Participants

The population in this trial was 288 1st- and 2nd-year medical and psychology students. Two hundred eighty-eight students were randomised, 144 to receive a 7-week MBSR programme and 144 students to the control group. They received no intervention and continued their studies as before. Data were collected before and after the intervention. Seven hundred four students were invited to participate, and 69 male and 219 female students took part. The mean age was 24 years, $70 \%$ were single, and $7 \%$ had children. Figure 1 shows the flow chart from the study. Details of the randomisation procedure and study recruitment are provided in the study of de Vibe (2013). 


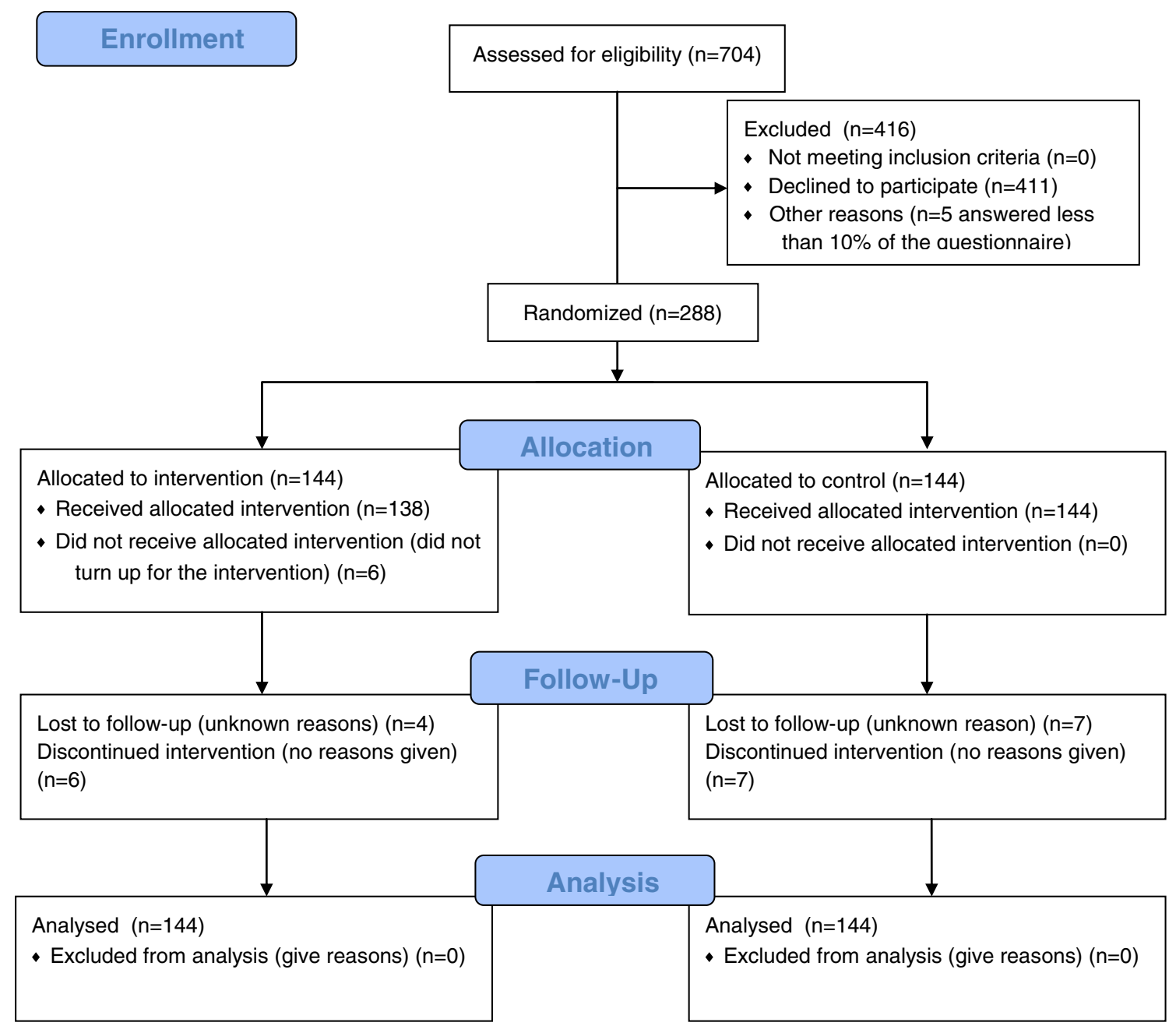

Fig. 1 Study flow chart

Measures

\section{Mental Distress}

The General Health Questionnaire (GHQ) (Goldberg and Williams 1988) was used to assess levels of mental distress experienced during the previous 2 weeks. It consists of 12 items, and responses are scored as ' 0 ' (much less than usual), ' 1 ' (less than usual), ' 2 ' (same as usual) or ' 3 ' (more than usual). The maximum score can range from 0 to 36 (high distress). The Norwegian version has shown good psychometric properties among 1st-year university students (Nerdrum et al. 2006). Internal consistency in our sample was Cronbach's alpha $=0.90$.

\section{Student Stress}

The 13-item Perceived Medical School Stress (PMSS) scale (Vitaliano et al. 1984) was used to measure student stress. The
Norwegian version has been validated in samples and cohorts of medical students (Bramness et al. 1991; Tyssen et al. 2001, 2007). In our study the word 'medical' was removed from the terms 'medical school' and 'medical training' to make all items relevant for both medical and psychology students. The PMSS uses a Likert scale ranging from 0 (strongly agree) to ' 4 ' (strongly disagree). The total score range is from 0 to ' 52 ' (high stress) and Cronbach's alpha was 0.79 for the whole sample ( 0.78 for medical students and 0.81 for psychology students).

\section{Subjective Well-being}

Subjective well-being (SWB) was measured using a Norwegian four-item scale (Moum et al. 1990) that assessed cognitive satisfaction, positive affect and negative affect. The number of response categories varied from 5 to 7 , and all items were therefore transformed to a $0-10$ scale. The mean sum of the four items was used with a range from 0 to 10 (high 
SWB). The Cronbach's alpha was 0.81. SWB has been validated both in Norwegian student and adult populations and has been shown to correlate strongly with Diener's 'Satisfaction with Life Scale' (Røysamb et al. 2002).

\section{Mindfulness}

The Five Facet Mindfulness Questionnaire (FFMQ) sum score was used to measure mindfulness. It has 39 items, and a Norwegian version has been validated in three samples of 792 1st-year Norwegian psychology students (Dundas et al. 2013). Item scores range from 1 (never or very seldom true) to ' 5 ' (very often or always true), and the total possible score range is from 39 to 195 (high mindfulness). The Cronbach's alpha of 0.79 reported for this study sample was similar to those reported in previous studies (Baer et al. 2006). The validity of the FFMQ is supported by studies showing positive correlations with meditation experience, openness to experience, emotional intelligence and self-compassion and negative correlations with psychological symptoms, neuroticism, thought suppression and difficulties with emotional regulation (Baer et al. 2006).

\section{Personality}

Personality traits were measured using the Norwegian 27-item Basic Character Inventory (BCI) (Torgersen 1980; Alnæs and Torgersen 1990) covering three dimensions, each measured using nine dichotomously scored items (the dimensional scores range from 0 to 9). The three dimensions were neuroticism (Cronbach's alpha $=0.75)$, conscientiousness (Cronbach's alpha $=0.68)$ and extroversion (Cronbach's alpha $=0.77)$. These personality traits have been validated previously in longitudinal studies of Norwegian medical students and young doctors (Kjeldstadli et al. 2006; Tyssen et al. 2007; Røvik et al. 2007).

\section{Statistical Analysis}

Intention-to-treat analyses were used. Missing data (4\%) were imputed using the last observation carried forward-a conservative statistical method when drop-out rates in the intervention and the control group are equal (Lane 2008). Bivariate (zero-order) correlation analyses were used to examine the relationships between the moderators and baseline levels of the outcome measures. Independent $t$ tests were performed to compare the personality factors of the male and female students.

Assuming that there is a gradual change in the effect of the intervention (predictor) depending on the level of the moderator, moderation can be examined by including the product of the predictor and the moderator as an interaction term in a multiple hierarchical regression analysis. To be statistically valid, moderators should be roughly equally distributed across study groups and not too highly correlated with the outcome variables (Baron and Kenny 1986). Multiple hierarchical regression analyses were performed separately for each outcome using unstandardised variables (Echambadi and Hess 2007). Each moderator was tested against all four outcomes. Gender was not stratified in the randomisation process, and men were over-represented in the control group (43 versus 26). Hence, gender was entered together with the baseline value of the outcome variable in the first step of the regression model. In the second step, the treatment (intervention versus control) and the moderator variable was entered. In the final step, the multiplied term of the treatment and the moderator variable was entered, representing the statistical test of moderation. Statistically significant moderators were examined visually by graphing the treatment effect on the outcome variable at different levels of the moderator. The Johnson-Neyman (J-N) technique was used to identify at what level of the moderator the moderation became statistically significant (Johnson and Neyman 1936).

\section{Results}

Descriptive statistics and correlation coefficients between all the baseline variables are reported in Table 1. In addition, all students were asked how often they practised mindfulness, and there was no difference between the groups. The correlation analyses showed that neuroticism was positively correlated with GHQ and PMSS and negatively correlated with SWB. Neuroticism showed an inverse correlation with FFMQ and extroversion and a positive correlation with conscientiousness. Women scored significantly higher than men on neuroticism (5.3 versus 3.6, $t_{286}=5.37, p<0.001$, $d=0.7)$ and conscientiousness (4.2 versus $3.4, t_{286}=2.61$, $p=0.01, d=0.4$ ), but not on extroversion (5.8 versus 5.2).

All significant regression coefficients are shown in Table 2, and the interaction effects are illustrated in Figs. 2, 3 and 4. Students with a higher baseline level of neuroticism reported a larger intervention effect on GHQ $\left(R_{\text {change }}^{2}=0.01, F_{1,282}=\right.$ $3.85, p=0.05)$ and on $\operatorname{SWB}\left(R_{\text {change }}^{2}=0.01, F_{1,282}=6.28, p=\right.$ $0.01)$ than students with a lower baseline level of neuroticism. The result for PMSS was not significant. In the treatment group, MBSR was found to lower mental distress (GHQ) and improve well-being (SWB) as baseline neuroticism increased, compared with the control group in which GHQ and SWB worsened with increasing neuroticism (Figs. 2 and 3). The J-N technique indicated a significant group difference on GHQ for students scoring $>1.1$ on the neuroticism scale $(90 \%$ of the students). For SWB, the interaction became significant for students scoring $>3.2$ on neuroticism $(67 \%$ of the students). 
Table 1 Correlations and descriptive statistics of predictors, moderators and baseline values of outcome measures $(n=288)$

\begin{tabular}{|c|c|c|c|c|c|c|c|c|c|}
\hline Variables & 1 & 2 & 3 & 4 & 5 & 6 & 7 & 8 & 9 \\
\hline 1. Group ${ }^{a}$ & - & & & & & & & & \\
\hline 2. GHQ & -0.05 & - & & & & & & & \\
\hline 3. PMSS & -0.05 & $.46^{* *}$ & - & & & & & & \\
\hline 4. SWB & -0.02 & $-0.73 * *$ & $-0.53 * *$ & - & & & & & \\
\hline 5. Gender $(0, q ; 1, \precsim)$ & $-0.14^{*}$ & $-0.17 * *$ & $-0.17 * *$ & 0.09 & - & & & & \\
\hline 6. Neuroticism & 0.07 & $0.46^{* *}$ & $0.52 * *$ & $-0.55^{* *}$ & $-0.30 * *$ & - & & & \\
\hline 7. Conscientiousness & -0.11 & 0.11 & $0.21 * *$ & -0.09 & $-0.15^{*}$ & $0.29 * *$ & - & & \\
\hline 8. Extroversion & -0.03 & -0.07 & $-0.15^{*}$ & $0.17 * *$ & -0.09 & $-0.21 * *$ & $-0.18 * *$ & - & \\
\hline 9. FFMQ & -0.06 & $-0.43 * *$ & $-0.39 * *$ & $0.54 * *$ & 0.05 & $-0.55^{* *}$ & -0.06 & $0.25^{* *}$ & - \\
\hline$M$ & 0.50 & 12.72 & 19.18 & 6.36 & 0.24 & 4.89 & 4.01 & 5.64 & 126.06 \\
\hline SD & 0.50 & 6.09 & 6.94 & 1.75 & 0.43 & 2.46 & 2.27 & 2.47 & 15.44 \\
\hline
\end{tabular}

GHQ General Health Questionnaire, PMSS Perceived Medical School Stress, SWB subjective well-being, FFMQ Five Facet Mindfulness Questionnaire $* p<0.05 ; * *<0.01$

${ }^{\mathrm{a}}$ Group: $0=$ control, $1=$ MBSR

Increasing levels of baseline conscientiousness indicated an increased effect of the MBSR intervention on PMSS $\left(R_{\text {change }}^{2}=0.01, F_{1,282}=6.28, p=0.01\right)$, compared to the control group which showed an opposite effect (Fig. 4). Conscientiousness did not moderate the effect of the intervention on SWB and GHQ. Applying the J-N technique yielded a significant conditional effect of conscientiousness on PMSS for students scoring $>3.6$ on the conscientiousness scale (52\% of the students). Extroversion and mindfulness were not significant as moderators.

\section{Discussion}

The moderation analyses in this study revealed that students who scored high on neuroticism benefitted more from the MBSR intervention and had lower levels of mental distress and increased subjective well-being post-intervention, compared to those in the control group. Graphing of the interaction effects indicates that the intervention may have protected students in the intervention group against the impact of increased mental distress and decreased subjective well-

Table 2 Hierarchical multiple regression analysis of significant interactions

\begin{tabular}{|c|c|c|c|c|c|c|}
\hline & \multicolumn{2}{|l|}{ GHQ } & \multicolumn{2}{|l|}{ SWB } & \multicolumn{2}{|l|}{ PMSS } \\
\hline & $\Delta R^{2}$ & $\beta$ & $\Delta R^{2}$ & $\beta$ & $\Delta R^{2}$ & $\beta$ \\
\hline Step 1 & $0.11 * * *$ & & $0.29 * * *$ & & $0.43 * * *$ & \\
\hline \multicolumn{7}{|l|}{ Control variables $^{\mathrm{a}}$} \\
\hline Step 2 & $0.12 * * *$ & & $0.05^{* * *}$ & & $0.02 *$ & \\
\hline Group & & $-0.36^{* * *}$ & & $0.22 * * *$ & & $-0.11 *$ \\
\hline Neuroticism & & 0.02 & & $-0.13^{*}$ & & \\
\hline Conscientiousness & & & & & & -0.07 \\
\hline Step 3 & $0.01^{\wedge}$ & & $0.02 * *$ & & $0.01 *$ & \\
\hline Group $\times$ neuroticism & & $-0.26^{*}$ & & $0.34 * *$ & & \\
\hline Group $\times$ conscientiousness & & & & & & $-0.24 *$ \\
\hline Total $R^{2}$ & $0.32 * * *$ & & $0.36 * * *$ & & $0.45^{* * *}$ & \\
\hline
\end{tabular}

Predicting GHQ and SWB from group, neuroticism and group $\times$ neuroticism and predicting PMSS from group, conscientiousness and group $\times$ conscientiousness; $N=288$; group: $0=$ control, $1=$ MBSR; gender: $0=$ female, $1=$ male

GHQ General Health Questionnaire, SWB subjective well-being, PMSS Perceived Medical School Stress

${ }^{\wedge} p=0.05 ;{ }^{*} p<0.05 ;{ }^{* *} p<0.01 ; * * * p<0.001$

${ }^{\text {a }}$ Control variables are gender and baseline value of the outcome variable 


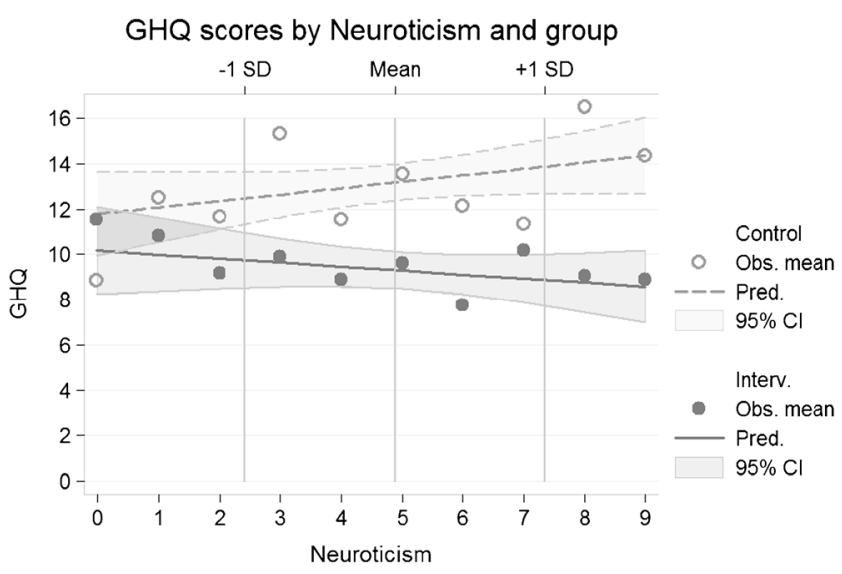

Fig. 2 Post-intervention scores for the General Health Questionnaire $(G H Q)$ by group and level of neuroticism. Neuroticism scores were unstandardised and adjusted for gender and baseline GHQ. Obs. mean observed mean, Interv. intervention, $S D$ standard deviation, $C I$ confidence interval

being associated with increasing levels of neuroticism that was observed in the control group. The effect of the intervention on reducing student stress was particularly evident in students who scored higher on conscientiousness. Baseline levels of extroversion and mindfulness did not moderate the effect of the intervention.

Neuroticism is an expression of emotional vulnerability and has been clearly linked to anxiety and depression in a recent meta-analysis of cross-sectional studies with control groups (Kotov et al. 2010). Neuroticism has been found to predict future student stress in a 6-year follow-up study of medical students (Tyssen et al. 2007), and a 15-year follow-up of medical doctors found neuroticism to be predictive of a three- to fourfold increase in the risk of severe depressive symptoms (Grotmol et al. 2013). Studies with psychology students have reported similar findings (Fetterman et al. 2010), in addition to an inverse relationship between

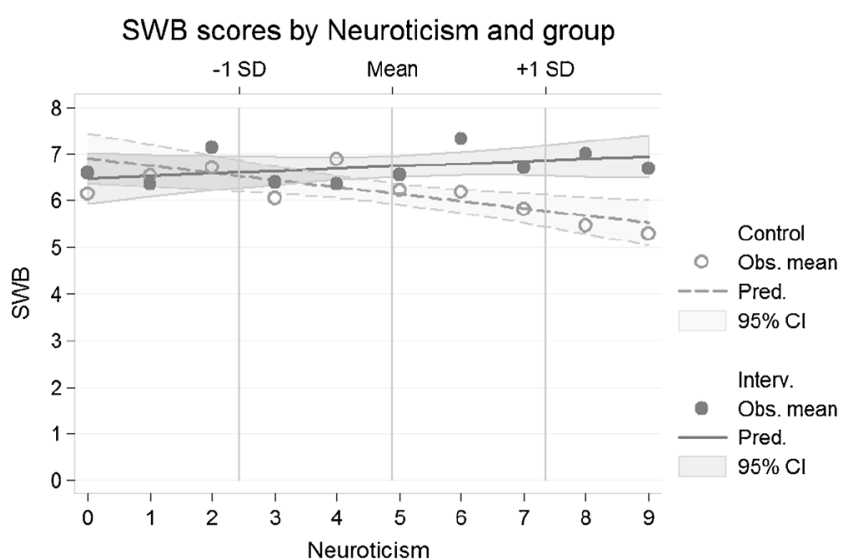

Fig. 3 Post-intervention scores for subjective well-being $(S W B)$ by group and level of neuroticism. Neuroticism scores were unstandardised and adjusted for gender and baseline SWB. Obs. mean observed mean, Interv. intervention, $S D$ standard deviation, $C I$ confidence interval

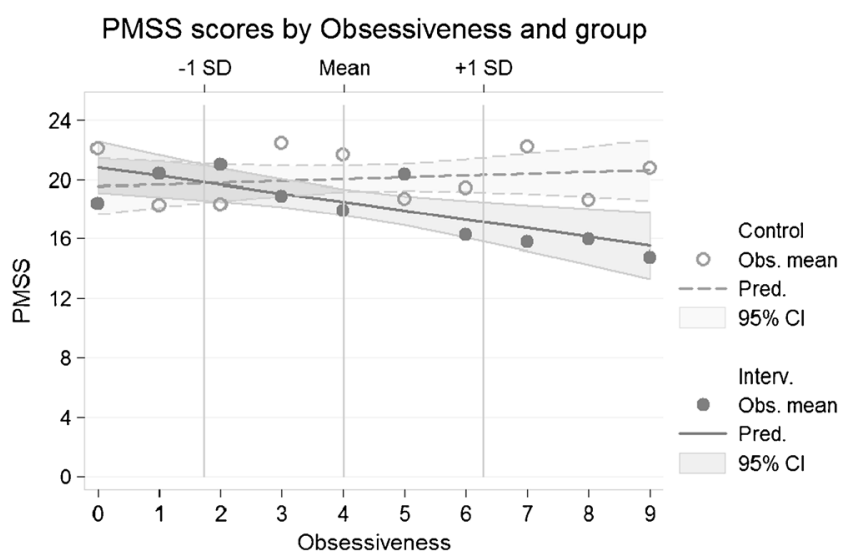

Fig. 4 Post-intervention scores for Perceived Medical School Stress (PMSS) by group and level of conscientiousness. Conscientiousness scores were unstandardised and adjusted for gender and baseline PMSS. Obs. mean observed mean, Interv. intervention, $S D$ standard deviation, CI confidence interval

neuroticism and mindfulness (Baer et al. 2006). This latter association has also been reported in a meta-analysis of 29 studies with adult populations (Giluk 2009). Similarly, our study showed a strong correlation in the expected direction between baseline values of neuroticism, mental distress, study stress, subjective well-being and mindfulness.

Changes in emotional processing may be a key to understand the protective benefits of mindfulness training for students with higher levels of neuroticism. Neuroticism may be conceptualised in terms of negative emotional reactivity processes (Feltman et al. 2009), and one may argue that individuals with higher emotional reactivity would benefit more from improving their emotional regulation skills to cope better with their emotional reactivity to stress (Connor-Smith and Flachsbart 2007). It is therefore promising that the J-N technique showed that the moderating effect of the MBSR intervention started at low levels of neuroticism and thus benefited the majority of the students. Emotional awareness, acceptance and letting go of negative thoughts - all related to mindfulness practice - are adaptive emotion regulatory strategies (Cordon et al. 2009). That mindfulness training is especially beneficial for students with high stress reactivity lends support to the notion that mindfulness training is an effective mechanism for the improvement of emotion regulation skills.

This is further supported by a study of undergraduate students which showed that increased levels of mindfulness reduced the relationship between neuroticism and the traits of anger and depression (Feltman et al. 2009). Mindfulness, as the authors showed, is not just an inverse representation of neuroticism but is a different psychological characteristic, and both variables predicted anger and depression when simultaneously controlled. The authors proposed that mindfulness training may be particularly beneficial for 
distress-prone individuals, and this claim is supported by our findings. Our gender analyses found that only female students benefited significantly from the intervention (de Vibe et al. 2013), and female students scored significantly higher on neuroticism and mental distress than male students. The level of neuroticism in women (both medical and psychology students) was also significantly higher $(t=5.35, p<0.0001)$ compared to a sample of 140 female Norwegian medical students in a 1993 study (Tyssen et al. 2007). No difference was found in the scores of male students. These findings further highlight the importance of targeting female students for stress management interventions.

The personality characteristic of conscientiousness predicted a differential effect of the intervention on study stress. The MBSR course had an increased effect on students with higher conscientiousness scores (half of the students in our sample). These students may have been more conscientious in terms of their treatment adherence and may therefore have benefited more from the intervention, although evidence for this was not found when comparing attendance rates and reported home practice. Another possibility is that the students who scored higher on conscientiousness may have responded positively to the acceptance and letting go attitude in their mindfulness training. The training may have offered them an alternative to their usual controlling way of relating to the world and to themselves. Over time, such training may influence this personality trait. Initial support for this claim can be found in a study comparing conscientiousness levels in 35 experienced mindfulness practitioners and 35 matched controls (van den Hurk et al. 2011). They found significantly lower scores on conscientiousness among the experienced mindfulness group. In line with this, an intervention study with practising doctors found that 1 year of mindfulness training lowered their level of conscientiousness (Krasner et al. 2009). In our study, the increased scores on study stress at post-intervention among the students in the control group with higher scores on conscientiousness suggest that these students may be more vulnerable to study stress and could thus benefit particularly from this type of intervention. Similar findings were shown in a study of perfectionism among medical students (Enns et al. 2001), which found that achievement striving was significantly correlated with conscientiousness and predictive of dissatisfaction with academic performance 6 months later. The female students in our study scored significantly higher than the male students on conscientiousness. Compared with the scores of female medical students in 1993 (Tyssen et al. 2007), the level of conscientiousness both for female medical and psychology students in our sample was significantly higher $(t=3.80, p<0.001)$, while no significant differences were noted for male students. This underlines the possible importance of offering mindfulness interventions to people who score high on conscientiousness.
The study intervention protected against the increased mental distress, study stress and lower subjective well-being that was seen in the control group at the post-intervention measurement (which occurred close to the end of term exams). These effects were more pronounced for those who scored higher on neuroticism and conscientiousness, and most of whom were female students. This may indicate that the female students reacted differentially to stress, a suggestion supported by a study showing that healthy men and women engage different neural networks when exposed to moderate psychological stress (Wang et al. 2007). High levels of neuroticism and conscientiousness may also contribute to increased stress reactivity. In Norway, the required entrance grades for medicine and psychology are now very high, and this type of mindfulness intervention may therefore be particularly pertinent to the increasing percentage of women studying these courses.

Contrary to our hypothesis, baseline levels of mindfulness did not moderate the intervention effect. However, a previous study (Shapiro et al. 2011) proposed that people with higher levels of mindfulness may find the mindfulness exercises less demanding to perform, thus leading to greater perceived mental health gains over time. Whether 2 and 4-year followup data from this mindfulness trial will confirm this remains to be seen.

The strengths of our study included the relatively large sample size taken from different student classes, universities and curricula. The outcome assessors were blinded to the identity of the participants, and different course instructors were used. However, several limitations were evident: first, because the randomisation was not stratified by gender, only 26 men received the intervention. This made separate gender analyses difficult. Secondly, the use of four possible moderators for each outcome may have increased the risk of false-positive findings. Thirdly, no effort was made to restrict or control possible communication between participants in the intervention and control group. As many of the participants had come from the same student classes and volunteered to participate in a stress management study, communication between them may have affected the results. Finally, only $40 \%$ of the eligible students participated in the study; a lack of information about the remaining students may therefore limit the generalisability of these findings.

In summary, we found that mindfulness training had greater effects on students with higher scores on the personality traits of neuroticism and conscientiousness. The majority of these students were female. There was an increase in mental distress and student stress and lower well-being in the control group after the intervention that was protected against by mindfulness training in the intervention group. These findings will need to be replicated before further, definite, conclusions can be drawn regarding which student groups should be targeted for mindfulness interventions. 
Acknowledgments We would like to thank Oluf Jensen at the Norwegian Knowledge Centre for the Health Services for putting the questionnaire online and for securing the randomisation and allocation process. We also wish to thank the Norwegian Medical Association, Helse Nord, and the Norwegian Knowledge Centre for the Health Services for funding this study.

Conflict of Interest The authors declare that they have no competing interests.

Open Access This article is distributed under the terms of the Creative Commons Attribution License which permits any use, distribution, and reproduction in any medium, provided the original author(s) and the source are credited.

\section{References}

Alnæs, R., \& Torgersen, S. (1990). Basic character inventory personality traits among patients with major depression, anxiety and mixed conditions. European Archives of Psychiatry and Neurological Sciences, 239, 303-308.

Baer, R. A., Smith, G. T., Hopkins, J., Krietemeyer, J., \& Toney, L. (2006). Using self-report assessment methods to explore facets of mindfulness. Assessment, 13(1), 27-45. doi:10.1177/1073191105283504.

Baron, R. M., \& Kenny, D. A. (1986). The moderator-mediator variable distinction in social psychological research: conceptual, strategic, and statistical considerations. Journal of Personality and Social Psychology, 51 (6), 1173-1182.

Bramness, J. G., Fixdal, T. C., \& Vaglum, P. (1991). Effect of medical school stress on the mental health of medical students in the early and late clinical curriculum. Acta Psychiatrica Scandinavica, 84, 340-345.

Brown, K. W., Ryan, R. A., \& Creswell, J. D. (2007). Mindfulness: theoretical foundations and evidence for its salutary effects. Psychological Inquiry, 18(4), 211-237.

Connor-Smith, J. K., \& Flachsbart, C. (2007). Relations between personality and coping: a meta-analysis. Journal of Personality and Social Psychology, 93(6), 1080-1107. doi:10.1037/0022-3514.93.6.1080.

Cordon, S. L., Brown, K. W., \& Gibson, P. R. (2009). The role of mindfulness-based stress reduction on perceived stress: preliminary evidence for the moderating role of attachment style. Journal of Cognitive Psychotherapy, 23(3), 258-269. doi:10.1891/0889-8391. 23.3.258

De Vibe, M., Bjørndal, A., Tipton, E., Hammerstrøm, K., \& Kowalski, K. (2012). Mindfulness based stress reduction (MBSR) for improving health, quality of life, and social functioning in adults. Campbell Systematic Reviews, 8, 3 .

de Vibe, M., Solhaug, I., Tyssen, R., Friborg., O., Rosenvinge, J., Sørlie, T., et al. (2013). Mindfulness training for stress management: a randomised controlled study of Norwegian medical and psychology students. MBC Medical Education, 13:107 http://www. biomedcentral.com/1472-6920/13/107. Accessed 10 Mar 2013.

Delmonte, M. M. (1988). Personality correlates of meditation practice: frequency and dropout in an outpatient population. Journal of Behavioral Medicine, 11(6), 593-597.

Diener, E. (2000). Subjective well-being - the science of happiness and a proposal for a national index. American Psychologist, 55(1), 34- 43. doi:10.1037/0003-066x.55.1.34

Dundas, I., Vøllestad, J., Binder, P.-E., \& Sivertsen, B. (2013). The Five Factor Mindfulness Questionnaire in Norway. Scandinavian Journal of Psychology, 54(3), 250-260. doi:10.1111/sjop.12044.

Echambadi, R., \& Hess, J. D. (2007). Mean-centering does Not alleviate collinearity problems in moderated multiple regression models. Marketing Science, 26(3), 438-445. doi:10.1287/mksc.1060.0263.
Enns, M. W., Cox, B. J., Sareen, J., \& Freeman, P. (2001). Adaptive and maladaptive perfectionism in medical students: a longitudinal investigation. Medical Education, 35(11), 1034-1042.

Eysenck, H. J. (1990). Dimensions of personality: 16, 5 or 3? - criteria for a taxonomic paradigm. Personality and Individual Differences, 12(8), 773-790.

Eysenck, H. J. (1994). An alternative five-factor model for personality. In C. R. Halverson Jr., G. A. Kohnstamm, \& R. P. Martin (Eds.), The developing structure of temperament and personality from infancy to adulthood (pp. 37-51). New York: Hillsdale.

Feltman, R., Robinson, M. D., \& Ode, S. (2009). Mindfulness as a moderator of neuroticism-outcome relations: a self-regulation perspective. Journal of Research in Personality, 43(6), 953-961. doi:10.1016/j.jrp.2009.08.009.

Fetterman, A. K., Robinson, M. D., Ode, S., \& Gordon, K. H. (2010). Neuroticism as a risk factor for behavioral dysregulation: a mindfulness-mediation perspective. Journal of Social and Clinical Psychology, 29(3), 301-321.

Giluk, T. L. (2009). Mindfulness, Big Five personality, and affect: a metaanalysis. Personality and Individual Differences, 47(8), 805-811. doi:10.1016/j.paid.2009.06.026

Goldberg, D., \& Williams, P. (1988). A User's guide to the general health questionnaire. Windsor: NFER.

Grotmol, K. S., Gude, T., Mourn, T., Vaglum, P., \& Tyssen, R. (2013). Risk factors at medical school for later severe depression: a 15-year longitudinal, nationwide study (NORDOC). Journal of Affective Disorders, 146(1), 106-111. doi:10.1016/j.jad.2012.08.047.

Hanstede, M., Gidron, Y., \& Nyklicek, I. (2008). The effects of a mindfulness intervention on obsessive-compulsive symptoms in a non-clinical student population. Journal of Nervous and Mental Disease, 196(10), 776-779. doi:10.1097/Nmd.0b013e31818786b8.

Johnson, P. O., \& Neyman, J. (1936). Tests of certain linear hypotheses and their applications to some educational problems. Statistical Research Memoirs, 1, 57-93.

Kazdin, A. E. (2008). Mediators and mechanisms of psychotherapy: changes are needed in the focus and design of psychotherapy research. International Journal of Psychology, 43(3-4), 210-210.

Kjeldstadli, K., Tyssen, R., Finset, A., Hem, E., Gude, T., Gronvold, N. T., Ekeberg, O., Vaglum, P. (2006). Life satisfaction and resilience in medical school-a six-year longitudinal, nationwide and comparative study. BMC Medical Education, 6, 48. http://www. biomedcentral.com/1472-6920/6/48. Accessed 10 Mar 2013.

Kotov, R., Gamez, W., Schmidt, F., \& Watson, D. (2010). Linking "Big" personality traits to anxiety, depressive, and substance use disorders: a meta-analysis. Psychological Bulletin, 136(5), 768-821. doi:10. 1037/A0020327.

Kraemer, H. C., Frank, E., \& Kupfer, D. J. (2006). Moderators of treatment outcomes - clinical, research, and policy importance. JAMA, 296(10), 1286-1289. doi:10.1001/jama.296.10.1286.

Krasner, M. S., Epstein, R. M., Beckman, H., Suchman, A. L., Chapman, B., Mooney, C. J., et al. (2009). Association of an educational program in mindful communication with burnout, empathy, and attitudes among primary care physicians. Journal of the American Medical Association, 12, 1284-1293.

Lane, J. D., Seskevich, J. E., \& Pieper, C. F. (2007). Brief meditation training can improve perceived stress and negative mood. Alternative Therapies in Health and Medicine, 13(1), $38-44$.

Lane, P. (2008). Handling drop-out in longitudinal clinical trials: a comparison of the LOCF and MMRM approaches. Pharmaceutical Statistics, 7(2), 93-106. doi:10.1002/Pst.267.

Moum, T., Naess, S., Sorensen, T., Tambs, K., \& Holmen, J. (1990). Hypertension labeling, life events and psychological well-being. Psychological Medicine, 20(3), 635-646.

Nerdrum, P., Rustøen, T., \& Rønnestad, M. H. (2006). Student psychological distress: a psychometric study of 1750 Norwegian 
1st-year undergraduate students. Scandinavian Journal of Educational Research, 50(1), 90-109.

Røvik, J. O., Tyssen, R., Gude, T., Moum, T., Ekeberg, Ø., \& Vaglum, P. (2007). Exploring the interplay between personality dimensions: a comparison of the typological and the dimensional approach in stress research. Personality and Individual Differences, 42, 1242-1256.

Røysamb, E., Harris, J. R., Magnus, P., Vittersø, J., \& Tambs, K. (2002). Subjective well-being: sex-specific effects of genetic and environmental factors. Personality and Individual Differences, 32(2), 211-223. doi:10.1016/s0191-8869(01)00019-8.

Sass, S. M., Berenbaum, H., \& Abrams, E. M. (2013). Discomfort with emotion moderates distress reduction in a brief mindfulness intervention. International Journal of Behavioral Consultation and Therapy, 7(4), 24-27.

Shapiro, S. L., Brown, K. W., Thoresen, C., \& Plante, T. G. (2011). The moderation of mindfulness-based stress reduction effects by trait mindfulness: results from a randomized controlled trial. Journal of Clinical Psychology, 67(3), 267-277. doi:10.1002/jclp.20761.

Torgersen, S. (1980). Hereditary-environmental differentiation of general neurotic, obsessive, and impulsive hysterical personality traits. Acta Geneticae Medicae et Gemellologiae, 29(3), 193-207.
Tyssen, R., Vaglum, P., Gronvold, N. T., \& Ekeberg, O. (2001). Factors in medical school that predict postgraduate mental health problems in need of treatment: a nationwide and longitudinal study. Medical Education, 35I(2), 110-120.

Tyssen, R., Dolatowski, F. C., Rovik, J. O., Thorkildsen, R. F., Ekeberg, O., Hem, E., et al. (2007). Personality traits and types predict medical school stress: a six-year longitudinal and nationwide study. Medical Education, 41(8), 781-787. doi:10.1111/j.1365-2923. 2007.02802.x.

van den Hurk, P. A., Wingens, T., Giommi, F., Barendregt, H. P., Speckens, A. E., \& van Schie, H. T. (2011). On the relationship between the practice of mindfulness meditation and personality - an exploratory analysis of the mediating role of mindfulness skills. Mindfulness, 2(3), 194-200. doi:10.1007/s12671-011-0060-7.

Vitaliano, P. P., Russo, J., Carr, J. E., \& Heerwagen, J. H. (1984). Medical school pressures and their relationship to anxiety. Journal of Nervous and Mental Disease, 172(12), 730-736.

Wang, J. J., Korczykowski, M., Rao, H. Y., Fan, Y., Pluta, J., Gur, R. C., et al. (2007). Gender difference in neural response to psychological stress. Social Cognitive and Affective Neuroscience, 2(3), 227-239. doi:10.1093/Scan/Nsm018. 